Surface Faithfulness Phenomena and the Consonantal Root in the Modern Hebrew Verb System

\author{
TOM RECHT \\ University of California, Berkeley
}

\title{
Introduction
}

The nature of Modern Hebrew verbal morphology is the subject of an ongoing debate. As a Semitic language, Hebrew has traditionally been considered a rootand-template language, in which most native words and all verbs are formed by the combination of a purely consonantal root and a template consisting of vowels, prosodic information (stress location), and zero or more affixes. However, it has been repeatedly observed (e.g. Bat-El 1994, Schwarzwald 2003, Bolozky 2005) that a number of phenomena in the modern verb system cannot be analyzed as resulting from templatic structures, since they appear to reflect surface faithfulness to forms other than a putative root. This has led some linguists, notably Bat El (2003a, 2003b) and Ussishkin (2005), to argue that Modern Hebrew should not be considered a templatic language at all, and that its morphological system can be adequately described using concatenation and 'melodic overwriting' (the replacement of a base vowel by a different vowel in inflection). This approach runs into at least two difficulties. An internal difficulty is the "problem of the source' (Prunet 2006): it turns out that no single verbal category can be consistently selected as a base from which all others are derived, so that such theories must posit different bases to suit the requirements of different verb classes and paradigms. An external difficulty is that psycholinguistic studies have consistently shown that verbal roots have a real status in Hebrew speakers' minds. This fact can be disregarded by models that aim at pure formalization of the phenomena and nothing more, but any theory that aspires to insight into Hebrew verb morphology as a living system cannot, it seems, do without a concept of the root.

This paper argues that from the point of view of speakers Modern Hebrew must be described as a hybrid system, possessing elements of both templatic and concatenative morphology, and that more generally, templaticity and concatenativity are not absolute, binarily opposed categories, but stand for bundles of 
morphological characteristics, of which a given language may possess a combination and which are subject to piecemeal diachronic change.

\section{Surface Faithfulness Phenomena in the Modern Hebrew Verb System}

At least three distinct sets of phenomena in the Hebrew verb system present features that can only be analyzed as preserving faithfulness to some other surface form, and thus cannot be captured in a purely templatic model. All are restricted to loan verbs (i.e. verbs directly borrowed from other languages) and to denominal verbs, which are often themselves formed from borrowed nouns. Two of these faithfulness phenomena - consonant cluster preservation and vowel preservation - have been described in the literature (e.g. Bolozky 1999, Schwarzwald 2003); a third, stress preservation, which is restricted to one or two colloquial verbs, has not to my knowledge been described before.

All these phenomena are new developments in Modern Hebrew - that is, they date from the $20^{\text {th }}$-century revival and later. To understand them, a brief description of the traditional Hebrew verb system, as presented in standard grammars (e.g. Gesenius 1910), will be useful.

The lexical portion of a Hebrew verb is a consonantal root, most often consisting of three consonants, but sometimes of two or four. This root is discontinuously combined with one of several paradigms of vowel sequences and affixes to produce a verb inflected for tense and for person, number and gender of the subject. These paradigms, known in the Hebrew grammatical tradition as binyanim ('constructions'; singular binyan), are traditionally said to be seven in total, though there are some additional minor subcategories and hybrid forms. The binyanim correspond quite loosely to grammatical categories such as voice, causativity and intensivity. Though generalizations of varying strength (mostly concerning thematic roles) are possible, it is often impossible to predict in which of the binyanim a given verb root will be inflected. Most verbs are realized in some subset of the seven binyanim; few are realized in all. (For an attempt at semantic and syntactic characterization of the binyanim, see Horvath 1981).

Importantly for the developments to be described, already in pre-Modern Hebrew different binyanim could accommodate different numbers of consonants: though most were limited to three (putting aside biliteral roots), some could contain either three or four. This flexibility in the consonantal structure of some of the binyanim arose from the fact that they contained geminate $\mathrm{C}$-slots, i.e. slots in which a root consonant surfaced as a geminate. Presumably due to a reinterpretation based on equivalence of timing units, already in the earliest attested Hebrew these slots had come to accommodate not only geminated root consonants but clusters of two distinct root consonants. This was the basis for the existence of quadriliteral roots, which could thus only be realized in the subset of binyanim (three out of the total seven) that contained geminate slots. In Modern Hebrew 
phonology, distinctive gemination has been lost, so that the timing-unit equivalence in these slots no longer holds; the possible significance of this fact will be considered below.

Table (1) shows the vowel and affix templates of the seven major binyanim, with their traditional names and characterizations, in the past, present, and future tenses. Within the past tense, some binyanim show vowel alternations between the third person (III) and the other persons (I, II). Subject-agreement affixes are the same in all binyanim and are not shown. $\mathrm{C}$ stands for a consonant slot, underlined $\underline{\mathrm{C}}$ for a geminated consonant slot.

(1) Templates of the seven traditional binyanim.

\begin{tabular}{|c|c|c|c|c|}
\hline & Traditional binyan & Past & Present & $\begin{array}{l}\text { Future, impera- } \\
\text { tive, infinitive }\end{array}$ \\
\hline 1 & $\begin{array}{l}\text { pa'al "simple" } \\
\text { nif'al "passive" }\end{array}$ & $\begin{array}{l}\mathrm{CaCaC}- \\
n i-\mathrm{CCaC}-\end{array}$ & $\begin{array}{l}\text { CoCeC- } \\
n i-\mathrm{CCaC}-\end{array}$ & $\begin{array}{l}-i-\mathrm{CCoC}-\sim \\
-i-\mathrm{CCaC}- \\
-i-\mathrm{CaCeC}-\end{array}$ \\
\hline 3 & hif'il "causative" & $\begin{array}{l}h i-\mathrm{CCiC}-(\mathrm{III}) \sim \\
h i-\mathrm{CCaC}-(\mathrm{I}, \mathrm{II})\end{array}$ & $m a-\mathrm{CCiC}-$ & $-a-\mathrm{CCiC}-$ \\
\hline 4 & $\begin{array}{l}\text { huf'al "causative } \\
\text { passive" }\end{array}$ & $h u-\mathrm{CCaC}-$ & $m u-\mathrm{CCaC}-$ & $-u-\mathrm{CCaC}-$ \\
\hline 5 & pi'el "intensive" & $\begin{array}{l}\text { CiCeC- (III) } \\
\text { CiCaC- (I, II) }\end{array}$ & $m e-\mathrm{CaCeC}-$ & $-e-\mathrm{CaCeC}-$ \\
\hline $5 a$ & polel & $\begin{array}{l}\text { CoㅡeC- }(\mathrm{III}) \sim \\
\mathrm{Co} \underline{\mathrm{C}} \mathrm{aC}-(\mathrm{I}, \mathrm{II})\end{array}$ & $\begin{array}{l}m e- \\
\text { CoCeC- }\end{array}$ & $-e-\mathrm{Co} \underline{\mathrm{CeC}}$ \\
\hline 6 & $\begin{array}{l}\text { pu'al "intensive } \\
\text { passive" }\end{array}$ & $\mathrm{CuCaC}-$ & $\begin{array}{l}m e- \\
\mathrm{CuCaC}-\end{array}$ & $-e-\mathrm{CuCaC}-$ \\
\hline 7 & hitpa'el "reflexive" & $\begin{array}{l}\text { hit-CaCeC- (III) } \\
\text { hit-CaCaC- (I, II) }\end{array}$ & $\begin{array}{l}\text { mit- } \\
\mathrm{CaCeC}-\end{array}$ & -it-CaCeC- \\
\hline
\end{tabular}

It will be seen that binyanim 5-7 contain a geminated middle C-slot; quadriliteral roots can thus be realized in these three binyanim, as $\mathrm{CiCCeC}$ etc. Note also that stress, although not shown in the table, is completely predictable: in unsuffixed forms, the second vowel of the template (that is, the last vowel in the word) is stressed; in forms with a subject-agreement suffix, some such suffixes attract the stress (e.g. pa'al-ú 'they acted'), others do not (e.g. pa'ál-ta 'you (m. sg.) acted').

The seven binyanim are divided in Table (1) into three groups based on productivity relations. Within each group, if a verb is realized in one of the binyanim, it will usually be realized in the others, but not necessarily in binyanim outside that group. Thus any verb with a form in binyan 5 is likely to have a passive in binyan 6 and a reflexive in binyan 7, but it will not necessarily have forms in binyanim 1-4. 
The binyan shown as 5a is a minor and largely unproductive pattern, in which the second and third consonants are always identical; it is traditionally considered a subtype of binyan 5 .

In terms of general productivity, the second and third groups of binyanim are productive in forming new verbs, while the first group (binyanim 1-2) and the minor pattern 5a are largely though not completely unproductive. The productivity of these latter binyanim seems to be restricted to cases in which their vowel structure contributes to maximal source faithfulness, as is described below.

I will now proceed to describe the three sets of surface-faithfulness phenomena in Modern Hebrew: consonant cluster preservation, vowel preservation and stress preservation. In all three cases, 'preservation' refers to the faithful reflection in some or all verb forms of a feature of some other, related form: either a noun, usually a loanword, from which the verb is denominalized, or a foreign source word of a loan verb. For brevity, I will refer to this form as the 'source' or 'source word' of the verb.

\subsection{Consonant Cluster Preservation}

In this type of surface faithfulness, the verb form preserves the consonant adjacency patterns of its source: clusters in the source word appear as clusters throughout the paradigm of the verb, rather than being broken up by template vowels. In many quadriliteral verbs this can be regarded as merely a side effect of the structure of the binyan, and therefore as analytically straightforward; in other verbs, however, some reference to properties of the source seems required. Consider first the following verbs in binyanim 5 ( $\mathrm{CiCCeC}$ ) and 7 (hit $\mathrm{CaCCeC})$ :

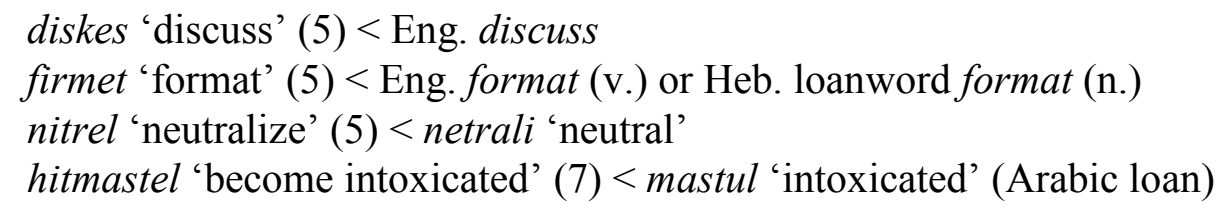

It will be seen that the source words contain a medial consonant cluster, and that this is accommodated naturally by the medial $\mathrm{C}$-slot of the relevant binyan (an originally geminate slot). Such forms therefore pose no difficulty in terms of a templatic analysis. Others, however, do:

Pibstrekt 'make abstract' $(5)<$ Pabstrakti

flirtet 'flirt' (5) < Eng. flirt

hišprits $(3)<\check{s}$ prits 'spray' (Yiddish loanword)

Pibstrekt and flirtet, both binyan-5 forms (CiCCeC), depart from the traditional form of this binyan in two ways. The medial C-slot in Pibstrekt contains not 
two consonants but four — an impossibility in pre-Modern Hebrew, where clusters of more than two consonants were not allowed. Also, clusters appear in the final C-slot (Pibstrekt) and the initial C-slot (flirtet) of the same binyan; these are not originally geminate slots, and could not have contained clusters in preModern Hebrew. Similarly, hišpric (binyan 3, hiCCiC) contains three consonants in two C-slots, neither of which is a geminate slot, so that one slot (presumably the second) must be regarded as containing a cluster.

The motivation for these structural departures is clear: in all cases, they preserve the consonant clusters of the source. Thus these forms cannot be analyzed as derived from a root (which would contain no information about segment adjacency) plus a template. The case of flirtet is especially instructive. The source word flirt contains four consonants; it would thus be possible to form this verb, in the same binyan, on the normal pattern $\mathrm{CiCCeC}$, yielding *filret. This does not occur; instead the initial cluster is preserved, with reduplication of the final consonant (an existing native morphological resource) to fill what would otherwise remain an empty C-slot. Similarly the source word špric 'spray', with its four consonants, might have yielded *šiprec in binyan 5; the actually occurring form is preferable only in the fact that it preserves the cluster $\check{s} p r$. (As the verb is not causative, there is no semantic reason for the choice of binyan 3.) It would be impossible to account for these verbs without reference to the form of the source, as any analysis must require ascribing a higher value to cluster preservation (seen as a sourcefaithfulness constraint) than to canonical template structure.

It seems, then, that in Modern Hebrew any C-slot, whether originally geminate or not, can accommodate consonant clusters when this is necessary for source faithfulness. The question arises why such departures from traditional template structure are allowable in Modern Hebrew at all. This is essentially a diachronic question, as we are dealing with a set of structural changes in the template system that have had the effect of increasing the flexibility of C-slots. A surely relevant factor is the fact that Modern Hebrew, unlike earlier forms of the language, permits complex syllable margins; this phonotactic flexibility is a necessary condition of the expansion of C-slot into cluster slots. Also relevant would seem to be the loss of distinctive gemination in the modern period. Before this change, the timing-unit equivalence between geminates and two-consonant clusters meant that the latter were limited to appearing only in geminate slots (and longer clusters could not appear at all, given the ban on complex margins). Once gemination was lost, nothing remained to distinguish the medial slots of binyanim 5-7 (the original geminate slots) from any others, and there would no longer have been any reason for speakers to learn that only those slots could accommodate clusters - a seemingly arbitrary restriction. The loss of gemination thus produced an equivalence between single consonants and clusters, which, once established, could spread into all C-slots in all binyanim. 


\subsection{Vowel Preservation}

A second strategy employed to increase faithfulness to the phonological form of source words exploits the fact that in some cases an element of a binyan (in some or all of its inflectional forms) happens to be identical to a substring of the source word. These serendipitous identities, which mostly involve vowels, often draw such words into the relevant binyan, even when it is otherwise generally unproductive as a template for new verbs. The result is that such a verb then contains a segment or string of segments which can be equally well analyzed as part or the template or as part of the root.

Many examples occur in binyan 3 ( $h i \mathrm{CCiC}$ ), in cases where the $i$ vowel of the template corresponds with an identical vowel in the source word:

$$
\begin{aligned}
& \text { hiflik 'hit, slap' }(3)<\text { flik 'blow' (Yiddish loanword) } \\
& \text { hišpric }(3)<\text { špric 'spray' } \\
& \text { hisnif 'snort' }(3)<\text { Eng. sniff } \\
& \text { hiklik 'click' (3) < Eng. click }
\end{aligned}
$$

This is a productive binyan, as mentioned above. Other cases, however, involve verbs formed in otherwise unproductive binyanim. These include verbs formed from source words containing the vowel $o$, which (as Table 1 shows) only occurs as a template element in two binyanim: the minor binyan 5a, whose first vowel is $o$ in all forms; and the non-past forms of the frequent but largely unproductive binyan 1. Both these binyanim attract verbs based on source words containing $o$ :

$$
\begin{aligned}
& \text { koded }(5 \mathrm{a})<\text { kod 'code' (English loanword) } \\
& \text { šnorer 'thieve' }(5 \mathrm{a})<\text { šnor 'theft, fraud' (Yiddish loanword) } \\
& \text { laxrop (inf.) }(1)<x \text { rop 'sleep' (Slavic loanword) }
\end{aligned}
$$

The choice between binyanim 1 and $5 \mathrm{a}$ in such cases seems to be based on both phonological and argument-structure criteria. Source words of the form $\mathrm{CCoC}$, like šnor and xrop, can fit into either binyan, but those of the form CoC can only go into $5 \mathrm{a}$, where the missing third consonant can be supplied by reduplication. In the case of $\mathrm{CCOC}$ words, the choice of binyan seems to be a question of the verb's argument structure: 5a, like its parent 5, is a strongly transitive binyan, while 1 contains both transitive and intransitive verbs. Since only a handful of relevant verbs exist, there is insufficient data for a positive conclusion, but it seems a plausible generalization that intransitive verbs based on $\mathrm{CCoC}$ words are formed in binyan 1, transitive ones in binyan $5 \mathrm{a}$.

A phenomenon similar to vowel preservation, but in which the element shared between source and template is longer than a single vowel, occurs in one word 
known to me: mesandzer 'make a messenger of'. The relevant template is $m e \mathrm{CaCeC}$, the present form of binyan 5 (where me- is a present-tense prefix). Here the identity between the me-prefix of the template and the first two segments of the source word is exploited to create a phonologically highly faithful denominal verb from a five-consonant source which is otherwise difficult to fit into any of the binyanim.

It should be noted that in most such cases, the identity between template elements and source-word segments only holds in part of the verbal paradigm, because template elements vary in inflection. Thus, as Table 1 shows, verbs like hiklik do not contain the relevant $i$ in the first- and second-person past forms, where the form is $h i \mathrm{CC} a \mathrm{C}$-; verbs like laxrop only contain $o$ in the infinitive and future; verbs like mesandzer have a me-prefix only in the present tense. Binyan 5a verbs like koded are exceptional in that the shared $o$ appears in all paradigm forms, but even such verbs will have non-faithful forms because of inter-binyan productivity: as described above, verbs in 5 (including 5a) regularly form passives in 6, where the shared $o$ does not occur (kudad 'was coded').

The strategy thus appears to be to realize such verbs in paradigms where at least some of the forms will be source-faithful. In some such verbs the choice of binyan is straightforward because only one binyan affords the necessary phonological element: a verb 'to make a messenger of' can only be formed faithfully in binyan 5, as no other binyan contains the prefix me-. Where competition between binyanim does arise, as in the case of source words of the form $\mathrm{CCoC}$, the choice seems to be motivated by the fit between the verb's argument structure and the prototypical lexical semantics of the binyan (cf. Horvath 1981).

Nonetheless, in parts of the paradigm where source faithfulness does hold, the result of this preservation strategy is to produce verb forms which can in principle be analyzed as composed of a stem, identical to the source word, plus affixes. Thus laxrop 'to sleep' and hiklik 'clicked', though still analyzable traditionally as consisting of the triliteral roots $x-r-p, k-l-k$ in the templates $l a \mathrm{CCoC}$ and $h i \mathrm{CC} i \mathrm{C}$, can also be seen as the stems klik and xrop (identical to borrowed nouns) preceded by the verbal inflection prefixes la- 'binyan 1 infinitive' and hi- 'binyan 3 past'. This stem-based analysis, though not extendible to the entire paradigms of these verbs, has the advantage, in those forms where it does apply, of accounting for the identity with the source words, which must otherwise be seen as coincidental. The faithfulness-increasing enlistment of serendipitously appropriate template elements thus has the effect of creating what is in effect stem-and-affix morphology in part or all of the verbal paradigm.

Just as in the case of cluster preservation, then, vowel preservation and associated phenomena present cases where a templatic analysis falls short. A templatic account, unable as it is to refer to related surface forms, cannot explain the choice of binyan in these forms, which is clearly motivated by source-word faithfulness. 


\subsection{Stress Preservation}

A final, recent development, not yet described in the literature to my knowledge, occurs in colloquial registers and is still very restricted in scope. This is the appearance of lexically determined stress in verbal forms. In traditional Hebrew morphology, the location of stress is as much a part of the verbal template as the vowel structure, and is completely predictable as described above (being either on the second template vowel, or on the suffix if that is one of the suffixes that attract stress). However, one or two colloquial loanword-based verbs (probably originating within the past twenty or thirty years, though such spoken-language innovations are hard to date) have an anomalous stress pattern:

histálbet 'make fun' (7) < stálbet 'fun, humor' (Arabic loanword)

This verb should be expected to receive regular second-template-vowel stress as *histalbét. That it does not do so, in violation of a strong morphophonological generalization, is surely related to the location of the stress in the base noun, which the verb thus preserves. Similarly to the case of vowel preservation, the result of stress preservation is that a form like histálbet is analyzable as a stem stálbet with inherent stress, preceded by an inflectional prefix hi-. The existence of the noun stálbet provides an argument for positing such a stem (and note that the choice of binyan 7 , hit $\mathrm{CaCeC}^{1}$, for this verb also has the effect of preserving both vowels of the source noun, so that the anomalous placement of the accent completes the identity between noun and verb stem). The alternative, templatic account is unable to refer to this noun and so cannot explain the anomalous location of stress in the verb. In the case of histálbet it is thus unavoidable to say that stress, which is normally specified by the template and affixes, is here specified lexically.

\section{Theoretical Accounts}

The phenomena just described are obviously difficult to account for in terms of Semitic root-and-template morphology as traditionally conceived, where consonantal slots are restricted to a single consonant each while vowels and stress are provided by the template alone. Some scholars have reacted to this difficulty by modifying or adding to the traditional account; others have taken the more drastic step of abandoning templatic morphology as a theoretical resource altogether, and attempting a purely concatenative account of the Hebrew verb system.

Bolozky (2005) accounts for cluster preservation by proposing the concept of the shorshan (pl. shorshanim), which he defines as "consonants or consonant sequences that are never split within the paradigm". These are intended as a way

\footnotetext{
${ }^{1}$ The metathesis $t s>s t$ is a regular phonological process.
} 
of capturing the structural significance of consonant clusters, which the traditional single-consonant slots fail to do. Bolozky's shorshanim differ from what I have referred to above as 'cluster slots', however, in that they are not stable across all verbal forms derived from a root. For example, a regular verb in binyan 1 has a past form $\mathrm{CaCaC}$ and an infinitive la $\mathrm{CCoC}$; in Bolozky's terms, the former has three shorshanim but the latter only two, since the first two root consonants form a cluster. Likewise, a verb in binyan $5(\mathrm{hiCCiC})$ and a verb from the same root in binyan $1(\mathrm{CaCaC})$ have different shorshanim - two in the former case, three in the latter. Obviously this misses the morphological similarity that the concept of a root is intended to capture; for Bolozky, then, the shorshan does not analytically replace the root, but complements it. It seems, however, that a simpler way of achieving the same result would be to modify the possible structure of the 'root' so that it consists of $\mathrm{C}^{*}$ units, i.e. either single consonants or clusters, than to posit two competing structures, a root and a set of shorshanim.

Several scholars, mostly working within Optimality Theoretic frameworks, have proposed the radical idea of dispensing with the consonantal root altogether in accounts of Hebrew (and Semitic) morphology. Instead, they favor the idea of 'melodic overwriting', in which a syllabic (rather than consonantal) input form serves as the basis for derivation, and other forms are produced by replacing or 'overwriting' the vowels of the base with the vowels of an affix. This approach has the advantage of accounting naturally both for cluster preservation and vowel preservation: the former because clusters contain no vowel that can be overwritten, the latter by positing a higher Optimality Theoretic constraint ranking for faithfulness to vowels present in the source word (which thus cannot be overwritten) than for other vowels. Proponents of such analyses include Bat-El (1994, 2003a, 2003b) and Ussishkin (2005).

A weakness of this type of analysis is that it offers no principled reason to choose one verb form rather than another as the 'base'. For a verb like gadal 'grow' it is equally possible to posit as the base form the past gadal and derive the present godel from it by melodic overwriting, or vice versa; neither alternative seems preferable. Bat-El concedes this, stating that the choice of base can vary between speakers and even at different stages of the same speaker's development, and that "semantic considerations may lead the learner to choose one form rather than the other" (2003b:24). Elsewhere she says:

I propose a structural interpretation of stem modification which expresses the morphological relations between stems in Semitic languages. The analysis takes a fully specified surface stem as the base of the operation rather than root and binyan. In many cases the phonological operations involved do not provide the clue for selecting the base and, for our purposes, it is actually not at all relevant. Lexical-semantic considerations ... are often responsible for selecting the base. (Bat-El 2003a:49-50) 
But the 'base' is only useful as a morphological construct; the reason for positing the existence of a base form is not that speakers ever show evidence of deriving one verb form directly from another, but that Optimality-Theoretic models like the one Bat-El uses require an input form. Absent independent evidence for its existence in the minds of speakers, the necessity for a concept of the 'base form' is unclear.

Ussishkin (2005) provides a similar 'melodic overwriting' theory of Hebrew verb derivation to that of Bat-El, with the difference that he identifies a single category - namely, the past tense of binyan 1, considered the least marked form - as the base. However, as he admits in a footnote (183), this poses the difficulty that the vowels of some verbs are unpredictable based on the past tense of binyan 1. Thus for example:

\begin{tabular}{ll} 
Binyan 1, III m. sg. past & Future \\
\hline kam 'get up' & ya-kum \\
sam 'put' & ya-sim \\
gar 'live' & ya-gur \\
šar 'sing' & ya-šir \\
lamad 'learn' & yi-lmad \\
lakad 'trap' & yi-lkod
\end{tabular}

As these examples show, the vowel of the future forms (and similarly of the infinitive and imperative) cannot be predicted based on the past forms: it varies between $u$ and $i$ in biliteral verbs, and between $a$ and $o$ in triliterals. This fact in itself seems sufficient to rule out any model which takes the binyan 1 past form as base and derives all others from it; and other candidates for the base are ruled out by Ussishkin himself on markedness grounds.

This 'problem of the source' — the lack of a single, fully informative form that can serve as a base for derivation - is the same argument advanced by Prunet (2006:45) against derivational accounts of verb morphology in other Semitic languages. It would seem that theories which necessitate a unidirectional derivation based on a single input form are simply not very fruitful as accounts of how speakers of Semitic languages actually produce verb forms.

In addition to these theory-internal problems encountered by proposals to do away with the consonantal root, there is ample external evidence from experimental studies in favor of the reality of the root as a psycholinguistic entity in Hebrew speakers' minds. Ravid and Bar-On (2005:234-236) provide a comprehensive review of such root-reality studies, both oral and written:

Studies of the acquisition of word-formation in Hebrew indicate an early ability to manipulate roots within spoken word structure. Berman (1990) shows that young Hebrewspeaking children rely on tri-consonantal roots as the least marked and most accessible 
option when forming denominative verbs. ... Similarly, both Berman (1994) and Ravid and Nir (2000) found that non-linear root-and-pattern affixation precedes linear suffixation in the acquisition of Hebrew adjectives. ... Berent and Shimron (1997) tested Hebrew readers' sensitivity to roots by obtaining ratings for vocalized nonce words with nonce roots. They found evidence of morphological decomposition and inferred the existence of the root morpheme as a separate representation in the Hebrew word. ... Frost, Forster and Deutsch (1997) studied the lexical representation of Hebrew words by testing adults on reading non-vocalized Hebrew words. They found that previous exposure to the root letters facilitated lexical access and naming of targets that were derivations of the root. Deutsch and Frost (2002) review a series of studies which suggest that regular root morphemes are lexically represented in the Hebrew mental lexicon. ... These studies, taken together, all indicate that roots are 'real' psychological entities in the sense that they play an important role in the organization of the Hebrew mental lexicon.

In light of these studies, it seems an unavoidable conclusion that any model of Hebrew verbal morphology that aims at psycholinguistic verisimilitude (rather than formal completeness only) must include a concept of the root. On the other hand, a pure root-and-template model is unable to account for the surfacefaithfulness phenomena described above. The only way out of the impasse, then, is to abandon the idea that templatic and concatenative systems are mutually exclusive, and describe the Modern Hebrew system as a hybrid of the two.

\section{Gradient Templaticity and Language Contact}

The idea that a morphological system can combine a degree of templaticity with a degree of concatenation is not, of course, a new one: Bat-El (2003a:30) herself states that 'the difference between Semitic and non-Semitic languages is not a matter of type but rather a matter of degree and combination.' But she assumes that the existence of the consonantal root depends on an all-or-nothing view of templaticity, and therefore takes these facts as militating against it, despite the root's experimentally demonstrated validity as a psycholinguistic entity. Yet if templaticity is a gradient, composite phenomenon, a more fruitful approach would be to seek the components that define the scale, i.e. the specific features that make a language more or less templatic. The surface-faithfulness phenomena considered above, all of which appear to have the effect of pulling the Hebrew system away from the maximally templatic pole of the continuum, may thus serve to identify some of the features of 'canonical' templaticity.

I suggest that each of the three sets of surface-faithfulness phenomena corresponds to the loss or erosion of a single canonical feature of maximally templatic languages, namely the following: 
1. Surface adjacency relations are templatically determined. In a prototypical templatic language, segment adjacency relations are never lexically specified: phonological structure derives from the template alone, so that the same root in different templates can yield (for example) the structures $\mathrm{C}_{1} \mathrm{C}_{2} \mathrm{VC}_{3}$ or $\mathrm{C}_{1} \mathrm{VC}_{2} \mathrm{VC}_{3}$. A fully templatic language cannot specify lexically that $\mathrm{C}_{1}$ and $\mathrm{C}_{2}$ must, or may not, surface adjacent to each other. But consonant cluster preservation in Modern Hebrew does exactly this: e.g. in flirtet 'flirt', the consonants $f l$ always surface adjacently, regardless of the template.

2. No overdetermination. By 'overdetermination' I mean a situation in which a single segment in a word appears to owe its existence to both the template and something else (a root or stem). In a canonical templatic language, all segments are singly determined: thus in 'ordinary' Hebrew verbs such as katav 'he wrote', the consonants $k-t-v$ are determined or contributed by the root alone, the vowels $a-a$ by the template alone. But vowel preservation (and the similar phenomenon exemplified by mesandzer) produces forms in which the preserved segment or string can - in fact, must - be ascribed both to the template and to the source noun. Thus the second $i$ of hiklik 'he clicked' reflects both the structure of the template $h i \mathrm{CCiC}$ as well as that of the source noun klik 'click'

3. Prosody is templatically determined. In a maximally templatic language, there is no lexical stress; the location of stress (if not fixed phonologically) is determined by the template. This is the case in practically all Modern Hebrew verbs; but in the case of histálbet 'made fun', the anomalous location of the stress must be ascribed to the source noun and is thus lexically determined.

All three sets of phenomena, then, represent cases in which some feature previously determined exclusively by the template ceases to be so, nudging Modern Hebrew a notch down (so to speak) on the templaticity scale.

The notion of a templaticity scale raises a number of distinct sets of questions: can such a scale be fully defined, and if so, what features define it? What constitutes a maximally templatic language? What factors cause languages to move up or down the scale? It would be beyond the scope of this paper to attempt to provide general answers to these questions, but the Hebrew data do indicate a possible partial answer to the last question, that of diachronic language change.

In the Hebrew case the motivation for all three types of 'anti-templatic' phenomena seems clear: speakers' desire to faithfully reflect the phonological structure of source words which, because of their foreign origin, are otherwise difficult to fit into the verbal system. An obvious fact about almost all the verbs in question, the relevance of which seems not to have been explicitly noted in previous work (oriented as this mostly is toward morphological theory), is that they are loan verbs: that is, either direct borrowings of foreign verbs or else denominal 
verbs formed from borrowed nouns. Their phonological structure is thus not straightforwardly 'translatable' into a native-like triliteral or quadriliteral root, either because they contain too many consonants, and/or because features other than the order and identity of the consonants (vowels, consonant adjacencies) are deemed important enough to merit preservation. Such difficulties tend not to arise in the case of denominal verbs formed from native nouns, as these are themselves generally based on a consonantal root which the verbal templates can easily accommodate.

Ultimately, then, the erosion of templaticity in Modern Hebrew is a language contact phenomenon, due to the influx of loanwords in the period dating from the modern revival. In terms of diachronic typology, the tentative generalization suggests itself that templatic systems are peculiarly vulnerable to such piecemeal erosion caused by lexical borrowing. Any morphological system that demands that lexical elements conform to a highly specific structure will be unfitted for accommodating loanwords that do not possess the required structure. In situations of language contact, such a system will therefore present speakers with an unusually sharp conflict between faithfulness to the shape of the source word and wellformedness in terms of the traditional morphology. The pragmatic effect of violating the former constraint is likely to be more serious than that of violating the latter: a verbal form which is insufficiently similar to its source word may not be understood (saying *filret for 'flirt' would probably stump most Hebrew speakers), while a form which merely presents a morphological anomaly will still be perfectly comprehensible.

With this in mind, it is unsurprising that comparable developments to those described here for Hebrew have been observed in other Semitic languages. Maltese has gone further than Hebrew along the path of loan verb accommodation, so that one Maltese conjugation class allows the wholesale importation of foreign stems which are then inflected with native affixes (Mifsud 1995, esp. ch. 5-6; Borg and Azzopardi-Alexander 1997:258ff.). Newton (1964; cited in Wichmann and Wohlgemuth 2008) describes a heavily Greek-influenced Arabic dialect of Cyprus in which Greek verbs are borrowed along with their native conjugations, so that all forms of these verbs are the same in both languages. Both of these cases, of course, represent situations of prolonged, intense contact with nonSemitic languages.

Finally, to return to the question of the status of the consonantal root. Both the synchronic analysis of templaticity as composite and the diachronic facts of gradual change along a templatic 'scale' indicate that an all-or-nothing view of the root (as either nonexistent or solely operative) is correspondingly misguided. Such a view would imply either that a language moving 'down' the templaticity scale must at some point lose all its roots in one fell swoop, or else that the root does not exist even in a maximally templatic language where no surfacefaithfulness phenomena occur (such as pre-Modern Hebrew), even though these 
are the chief argument against its existence. It seems clear that we will have to speak of coexisting domains of root-and-template and stem-and-affix morphology within the same language, or of competing templatic and concatenative subsystems; the nature and interaction of these subsystems in a given language cannot be defined a priori but can only be identified through psycholinguistic studies.

\section{References}

Bat-El, Outi. 1994. Stem modification and cluster transfer in Modern Hebrew. Natural Language \& Linguistic Theory 12:571-596.

Bat-El, Outi. 2003a. Semitic verb structure within a universal perspective. In J. Shimron, ed., Language, Processing, and Language acquisition in a Rootbased Morphology. Amsterdam: John Benjamins. pp. 29-59.

Bat-El, Outi. 2003b. The fate of the consonantal root and the binyan in Optimality Theory. Recherches Linguistiques de Vincennes 32:31-60.

Berent, I. \& Shimron, J. 1997. The representation of Hebrew words: Evidence from the obligatory contour principle. Cognition 64: 39-72.

Bolozky, Shmuel. 1999. Measuring Productivity in Word Formation: The Case of Israeli Hebrew. Leiden: Brill.

Bolozky, Shmuel. 2005. Linear first-time derivation of verbs and consonant cluster preservation in Israeli Hebrew. In Ravid, Dorit, and Hava Bat-Zeev Shyldkrot, eds., Perspectives on Language and Language Development. Dordrecht: Kluwer, 35-43.

Borg, Albert J., and Marie Azzopardi-Alexander. 1997. Maltese. Routledge.

Deutsch, A. \& Frost, R. 2002. Lexical organization and lexical access in a nonconcatenated morphology. In J. Shimron, ed., Language processing and acquisition in languages of Semitic, root-based morphology, 165-186. Amsterdam: Benjamins. Ephratt, M. (1997). The psycholinguistic status of the root in Modern Hebrew. Folia Linguistica, 31, 77-103.

Frost, R., Forster, K., \& Deutsch, A. 1997. What we can learn from the morphology of Hebrew. A masked-priming investigation of morphological representation. Journal of Experimental Psychology, Learning, Memory, and Cognition 23, 829-856. 
Gesenius, Wilhelm. 1910. Gesenius' Hebrew Grammar. Oxford: Clarendon (2nd English edition by K. Kautzsch, revised in accordance with the 26th German edition by A.E. Cowley. 1st German edition 1813).

Goral, M. \& Obler, L. K. 2002. Root-morpheme processing during word recognition in Hebrew speakers across the adult life span. In J. Shimron, ed., Language processing and acquisition in languages of Semitic, root-based morphology, 223-242. Amsterdam: Benjamins.

Horvath, Julia. 1981. On the Status of Vowel Patterns in Modern Hebrew: Morphological Rules and Lexical Representation', in T. Thomas-Finders, ed., Extended Word-and-Paradigm Theory, UCLA Occasional Papers in Linguistics 4, 228-261.

Mifsud, Manwel. 1995. Loan Verbs in Maltese: A Descriptive and Comparative Study. Leiden: Brill.

Newton, Brian. 1964. An Arabic-Greek Dialect. In Papers in Memory of George C. Pappageot. Supplement to Word 20. 43-52.

Prunet, Jean-François. 2006. External evidence and the Semitic root. Morphology $16: 41-67$

Ravid, Dorit. 2006. Word-level morphology: A psycholinguistic perspective on linear formation in Hebrew nominals. Morphology 16:127-148.

Ravid, Dorit, and Amalia Bar-On. 2005. Manipulating written Hebrew roots across development: The interface of semantic, phonological and orthographic factors. Reading and Writing 18:231-256

Schwarzwald, Ora. 2003. Transition in Modern Hebrew Word Formation: From Discontinuous to Linear Formation. In Proceedings of XVII International Congress of Linguists, Prague, Czech Republic, July 24-29, 2003.

Ussishkin, Adam. 2005. A fixed prosodic theory of nonconcatenative templatic morphology. Natural Language \& Linguistic Theory 23: 169-218

Wichmann, Søren, and Jan Wohlgemuth. 2008. Loan verbs in typological perspective. In T. Stolz, D. Bakker, and R. Salas Palomo, eds., Aspects of language contact. Mouton de Gruyter: 89-121. 
Tom Recht

\author{
Tom Recht \\ University of California, Berkeley \\ Department of Linguistics \\ 1203 Dwinelle Hall \\ Berkeley, CA 94720-2650 \\ trecht@berkeley.edu
}

